Revista Iberoamericana, Vol. LXXVI, Núm. 230, Enero-Marzo 2010, 41-61

\title{
VOZES NA FRONTEIRA: UMA OUTRA LEITURA PARA CAMINHOS E FRONTEIRAS DE SÉRGIO BUARQUE DE HOLANDA
}

\author{
POR \\ Silvana Seabra \\ Vanderbilt University
}

Caminhos e fronteiras de Sérgio Buarque de Holanda, lançado em 1957, não é dos livros mais lidos daquele autor, nem é, por certo, obra de um historiador típico. É sobretudo um livro de pretensões antropológicas e etnográficas, embora se coloque, no final, a serviço de uma reflexão sobre processos históricos. É mais bem compreendido ao lado de outro trabalho, Monções, publicado doze anos antes, e também de Extremo oeste, de 1976. De maneira geral, os três trabalhos tratam da história dos paulistas e da conquista do oeste brasileiro pelas "entradas e bandeiras” efetuadas ao logo dos séculos dezessete e dezoito. Os capítulos do livro vieram a público antes de sua publicação, na forma de artigos para o jornal O Estado de S. Paulo, entre 1946 e 1949. Os estudos de Sérgio Buarque sobre o bandeirantismo inserem-se num debate então razoavelmente difundido por autores como Alfredo Ellis Jr., Affonso d'Escragnolle Taunay e Alcântara Machado. Diante de tais questões que, em geral, definiram os bandeirantes como desbravadores que levaram a civilização onde reinava a barbárie, o livro se tornou "próprio das ciências sociais e históricas" e nunca ganhou outras leituras para além deste paradigma. Contudo, mesmo no interior do cânone das Ciências Humanas Sociais, Caminhos e fronteiras sempre foi de difícil catalogação, porque apela ora para a história, ora para a antropologia, ora para a geografia física e humana. Quando comparado a Raízes do Brasil, publicado em 1936, sugere a abordagem de um tema mais circunscrito e preciso. Porém, embora com enfoque diferente, Caminhos e fronteiras assinala aquela razão última que parece perseguir Sérgio Buarque e éresumida por Fernando Novais em prefácio à atual edição, na qual afirma ser "importante reler o conjunto do ponto de vista de sua unidade: a persistente e quase obsessiva indagação do mesmo objeto, genialmente fixado em Raízes do Brasil - entender por que nos sentimos "desterrados em nossa própria terra" (Novais 7). Se atentarmos às datas em que foram escritos os artigos que compõem Caminhos e fronteiras, poderemos sugerir uma ligação com os processos identitários próprios à época do Movimento Modernista e seus momentos seguintes, movimento ao qual Sérgio Buarque, embora 
nunca diretamente filiado, esteve, de certa forma, envolvido. Os anos 30 foram marcados por outra corrente que não se afastou do projeto modernista de fundo identitário, ao apontar para uma temática regionalista. Em muitos casos, tratavase de perceber o Brasil como a soma dos elementos regionais e, nesse sentido, a dimensão local acabava recobrindo-se de uma razão última, que não deixava de ser a nacional. São exemplos dessa literatura local os estudos de Gilberto Freyre sobre o Nordeste e os de Vianna Moog sobre o Sul. Comentando esse tipo de literatura e seus conflitos, Ettore Finazzi-Agrò observa:

A escolha de espelhar, por outro lado, o Brasil no sertão e de apresentar, pelo outro, o sertão como metonímia do Mundo - isto é, de incluir o País nos confins da Região e de dilatar a dimensão regional até a com-fundir num espaço-tempo universal-acaba por delinear uma ideologia peculiar, ou melhor, uma "possibilidade de convívio político” em que se combinam, misturam-se sem nunca se resolver ou se dissolver uma na outra, duas diversas (e até opostas) imagens/idéias da Nação: uma ligada, mais uma vez, à visão histórica de um Brasil-arquipélago, composto por junção de diferentes tradições ou de realidades distintas (raciais, étnicas, geográficas...); a outra, considerando-se o País na sua totalidade ideal e, ao mesmo tempo, característica, que o coloca, como (id)entidade única e incontrovertível como espaço-tempo continental, no contexto histórico e sociopolítico global. (Finazzi-Agrò, Um lugar 105-06)

A citação, ainda que inspirada pela obra de Guimarães Rosa, condiz com o argumento apresentado anteriormente. No caso de Caminhos e fronteiras, o tema parece incluído na linhagem que associa à modernidade os territórios apartados da contemporaneidade. Se há uma permanência da temática, parece haver também uma inflexão. Enquanto que em Raízes do Brasil o foco era a questão temporal, em Caminhos e fronteiras a questão espacial traduz-se na noção de fronteira/ movimento.

Na continuidade do argumento, também do ponto de vista epistemológico, algo novo é incorporado a essa mudança. Enquanto que uma das mais fortes correntes de leitura de Raízes do Brasil qualifica tal obra como uma “crônica do atraso" ou como inapelável descrição da força ibérica sobre as forças da modernidade, Caminhos e fronteiras parece abrir um outro flanco: a história nacional se desloca para a esfera interna, na qual a mobilidade e o tipo da ocupação do espaço dinamizam o legado ibérico, tornando-o passível de alterações.

Se a passagem do tempo para o espaço está expressa, de certa forma, na passagem de Raízes do Brasil para Caminhos e fronteiras, questões laterais tornam mais significativa a forma desse processo. Ao fim e ao cabo, em Caminhos e fronteiras é narrada, mesmo obliquamente, uma história da ocupação. E obras que têm como temática o espaço não abandonam, mas incorporam a noção de tempo. A temática do

Revista Iberoamericana, Vol. LXXVI, Núm. 230, Enero-Marzo 2010, 41-61
ISSN 0034-9631 (Impreso) 
espaço é então tratada como um dos pilares da formação nacional. De certa maneira retoma-se, em outras bases, a incursão/narrativa já analisada por Flora Süssekind (1990) a respeito dos viajantes. No entanto, se naquele momento a paisagem é descrita através de um inventário seguido de um movimento que classifica, ordena e organiza, após o final do século dezenove a questão epistemológica se trava em outro território. Nosso autor, alocado no campo da ciência e da objetividade, mesmo sem abraçar um modelo nomológico ${ }^{1}$, não tem, diante de si, a pena livre; seus tropos não são os da ficção. A pretensão é a de descrever o mais fielmente possível as terras e os processos de tomada das terras. Se a objetividade não é alcançada, sua intenção resulta numa obra significativamente diferente dos projetos ficcionais românticos. Mesmo assim, vale comparar alguns elementos contextuais ampliados.

\section{OUTRAS LEITURAS}

Os trabalhos que compartilham da temática da ocupação do espaço à época em que Sérgio Buarque escreve Caminhos e fronteiras tratam, em geral, de estabelecer o próprio e o alheio ou o puro e o impuro. Continua a discussão da identidade; no entanto, sopram nessa época os ventos do Modernismo. Anteriormente, o binarismo separava a civilização, representada pelo europeu, da barbárie, representada pelo nativo; e o problema residia na possibilidade de implementar ações civilizatórias. Os escritos pós-anos 1920, ligados à corrente Modernista, por sua vez, questionam internamente a nossa própria condição. O padrão evolucionista é abandonado em prol de uma perspectiva relativista, que valoriza as possibilidades culturais internas. O exemplo mais conhecido são a Caravana Modernista e os artistas da Semana de Arte Moderna de 22, que buscaram um substrato da nossa cultura que, anexado à contemporaneidade, fixaria algo próprio.

O recurso à leitura dos romances históricos do final do século dezenove (entre 1880 e 1900), também sugere um outro caminho que, como observou Franco Moretti (2003), passam-se em cenários fronteiriços: florestas, litorais, grandes extensões territoriais, montanhas. Também se situam na periferia do mundo, ou na fronteira do centro, como os romances Waldemar, o Vitorioso (1826) de Bernhard Ingemann, que retrata basicamente o conflito do reino dinamarquês contra o Santo Império Romano; A filha do capitão, romance do século dezoito, de Aleksandr Sergeevich Pushkin, que trata dos conflitos entre russos e cossacos; ou ainda Waverley, de Walter Scott (1814), que se passa na fronteira anglo-escocesa. Todos os exemplos,

\footnotetext{
1 Modelo de ciência baseado na possibilidade de leis. A sociologia do século dezenove, em especial a sociologia alemã. propôs uma longa discussão sobre a possibilidade ou não de abraçar um modelo de caráter nomológico para as ciências humanas. Os escritos de Sérgio Buarque foram fortemente influenciados pela escola alemã de Dilthey (1983) e Weber (1989).
}

\footnotetext{
ISSN 0034-9631 (Impreso)
} 
de tropos diversos, mostram que há algo mais substancial e sólido em termos de uma realidade partilhada: a construção da realidade nacional. Para Moretti, "longe de ser acidental, essa constante geográfica é provavelmente um importante fator do sucesso excepcional dos romances históricos, porque oferecem à Europa oitocentista uma verdadeira fenomenologia da fronteira” (Moretti 46).

Embora Moretti estude o romance, sua perspectiva sobre a questão da fronteira aproxima-se da perspectiva de Sérgio Buarque, para quem a nacionalidade também se funda nos limites territoriais. Em Moretti, as fronteiras podem ser externas - Estado contra Estado, numa disputa cujo mote é a aventura do enfrentamento do outro, em geral o inimigo - ou internas, que geralmente "operam de maneira diferente e focam um tema muito menos vistoso do que a aventura, mas muito mais perturbador: a traição" (Moretti 46). No caso de Sérgio Buarque, entretanto, a montagem é mais complexa. Em primeiro lugar, a fronteira sergiana não estabelece contigüidade com a noção de espaço. Em vez de uma demarcação político-social típica da nação, Caminhos e fronteiras projeta, antes, um ambiente antropológico:

Fronteira, bem entendido, entre paisagens, populações, hábitos, instituições, técnicas, até idiomas heterogêneos que aqui se defrontavam, ora a esbater-se para deixar lugar à formação de produtos mistos ou simbióticos, ora a afirmar-se, ao menos enquanto não a superasse a vitória final dos elementos que se tivessem revelado mais ativos, mais robustos ou melhor equipados. (12-13)

Se tomarmos a categorização de Moretti, a concepção aponta para noção de enfrentamento indicada pelos termos “defrontar”, "superar" e "vitória”. O conceito é reafirmado quando somado ao de aventura, que de fato aparece em Raízes do Brasil e que, em Caminhos e fronteiras, embora não se evidencie de modo explícito, não pode ser descartado. Assim, uma fronteira interna, cuja prática é a da aventura, se expressaria na comoção do suspense, do perigo, não fosse o fato de que, na continuidade do texto, a idéia de enfrentamento é substituída pela de adaptação, condição que o português traz como significativa vantagem.

A versão de fronteira assim estabelecida gera, por seqüência, à semelhança do romance histórico, uma leitura do tempo no espaço, como cita Moretti, lembrando as discussões de Bakhtin sobre o romance moderno (Bakhtin, "Formas de tempo e de cronotopo no romance”). A fronteira sergiana não é diferente. Essa abordagem, mesmo que não seja efetivamente espacializada, permite ao autor idas e vindas no curso do tempo.

O trabalho de Sérgio Buarque, obviamente, estabelece outros topoi. No entanto, as camadas temporais fazem de Caminhos e fronteiras uma verdadeira cartografia temporal engendrada da cartografia das fronteiras. E assim como na fronteira não acontece a contemporaneidade - o "não acontecimento" do centro nos romances

Revista Iberoamericana, Vol. LXXVI, Núm. 230, Enero-Marzo 2010, 41-61
ISSN 2154-4794 (Electrónico) 
históricos -, também a fronteira sergiana situa o acontecimento num lugar entre o nativo, ou as formas instituídas num “antes”, e o que veio com a colonização. Nesse sentido, toda fronteira é uma zona babélica na qual se chocam formas compósitas de tempos distintos.

Moretti define o romance moderno como gênero necessário a um Estado histórico de formação não homogênea. Ao definir uma espécie de modelo necessário de escrita, Moretti se torna quase um funcionalista, ainda na medida em que, para ele, o romance responde a um tipo de demanda política. Em Caminhos e fronteiras, as várias cartografias se põem a serviço de um outro desenho nacional. Mas o interessante é observar o desenho que se forma. Se, de fato, o acontecimento da fronteira é fora do centro, ele poderá ser a configuração da desigualdade, não necessariamente social, mas temporal e sobretudo cultural. A lógica de Moretti parece acompanhar muito de perto a versão de Benedict Anderson (1989) sobre a nação como narrativa e a de Doris Sommer (2004) sobre histórias de casais apaixonados em romances latinoamericanos. O pensamento de Benedict Anderson (15) poderia ser perfeitamente aplicável aqui, apenas substituindo a expressão “comunidade da nação” pela palavra "fronteira”: “As comunidades [ou as fronteiras] não devem ser distinguidas por sua falsidade/autenticidade, mas pelo estilo em que são imaginadas”.

Contudo, mais uma diferença deve ser apontada: ao descrever a fronteira, Sérgio Buarque não se refere à adaptação de forma metafórica, mas a presentifica explicitamente, alicerçada pela teoria da fronteira de Frederick Turner. Turner apresentou suas idéias no final do século dezenove, mais precisamente em 1893, sob o título The Significance of Frontier in American History em conferência da AHA (American Historical Association). De imediato suas afirmações tiveram pouco impacto, mas com o tempo suas idéias representariam uma opção explicativa para a construção da cultura e valores dos Estados Unidos. ${ }^{2}$ Segundo a teoria de Turner, o homem aculturado, quando enfrenta um território desconhecido, perde a conexão com a civilização, adapta-se às condições primitivas, para depois, num processo contínuo, voltar a evoluir. Nesse sentido, por sua defesa da harmonia, a fronteira sergiana sequer desempenharia um papel sedutor. Tal afirmação faria sentido não fosse o desequilíbrio lançado internamente pelo elemento "caminho", que faz com que o projeto das fronteiras seja um continuum.

\footnotetext{
2 A teoria da fronteira de Frederick Jackson Turner apresentava aos historiadores a possibilidade de discutir a história dos Estados Unidos a partir de uma perspectiva interna e não mais como um legado inglês. A novidade de Turner no que concerne ao conceito de fronteira foi tratá-lo dentro do sentido de encontro entre civilização e selvageria ou civilização e terras livres e não apenas no seu sentido europeu de limite entre duas nações, ou dois contingentes culturais. Sérgio Buarque parece ter sido atraído, exatamente, pela perspectiva de Turner quando da sua primeira estadia nos EUA em 1941. Sobre a discussão das filiações de Sérgio Buarque e Turner ver em especial Wegner, capítulo cinco.
}

Revista Iberoamericana, Vol. LXXVI, Núm. 230, Enero-Marzo 2010, 41-61
ISSN 2154-4794 (Electrónico) 
Além da instabilidade social, que traduz a tensão Sudoeste versus Nordeste - mais do que litoral versus interior -, também parece haver uma correlação entre a escrita e o espaço. A escrita do espaço do desconhecido e do encontro tenso do caminho que dinamiza a fronteira deve ser feita em pormenor, numa seqüência expositiva quase didática. Afinal, trata-se de um espaço desconhecido, o que torna o percurso uma aventura. Assim, o leitor é conduzido para dentro de um território que não lhe é familiar. A tensão é lançada mais uma vez: a geografia exige uma escrita. Contudo, se nos romances históricos a figuratividade aumenta na região da fronteira - porque "o espaço e os tropos se entrelaçam [e] a retórica depende do espaço", como nos lembra Moretti (54) -, numa obra não ficcional a resolução se mantém em solo diverso.

Mais do que isso, a imaginação da fronteira de Sérgio Buarque, sustentada na teorização de Turner, deve levar em conta o "outro" num equilíbrio também textual. Dessa forma, a escrita se desloca constantemente para fora de si na busca da linguagem do outro. Ocorre em Sérgio Buarque o oposto do que Moretti sugere sobre a lenta diminuição do uso da metáfora e sua substituição por predicados analíticos. Segundo Moretti (56), tal estratégia é utilizada porque a fronteira deve existir num breve período de tempo e desaparecer depois para dar espaço à nação cada vez mais homogênea. A narração detalhada faz da conquista um espaço lógico contínuo. ${ }^{3}$

De acordo com Moretti, portanto, o espaço/fronteira, determina que uma escrita avance como o próprio movimento social. Contudo, o conceito de fronteira em Caminhos e fronteiras tem, sobretudo, forte caráter antropológico . Não se trata de um avanço sobre o desconhecido, homens de um Estado tomando outro, ou uma sociedade avançando sobre o novo. Trata-se de um encontro entre "paisagens, populações, hábitos, instituições, técnicas, até idiomas heterogêneos” (12). Note-se que os elementos em questão são diversos na sua origem, o que abre de maneira profunda o leque para a questão da língua e da narrativa.

Além desse item não pouco perturbador, ao explicitar a adaptação e pretender um equilíbrio entre as culturas, não é mais possível fazer desaparecer as diferenças que se expressam através de metáforas, criando lentamente um mundo contido, como as várias narrativas de viagem. Sérgio Buarque, ao fundar a equivalência das culturas, precisa manter os outros mundos na sua multiplicidade ena sua integridade, também no nível da linguagem. Disso resulta a inexistência de um trajeto só no

\footnotetext{
3 Para tanto, Moretti recorre ao uso do que chamou de "moeda corrente intelectual única”, conceito que retira de Gellner e que remete à necessidade dos estados nacionais de estabelecerem uma língua única. Em outro matiz, encontramos a versão de Anderson, que investiga o desaparecimento do latim como língua dos documentos e das classes altas para dar lugar às línguas "bárbaras", as quais corresponderiam, por sua vez, às unidades nacionais.
}

Revista Iberoamericana, Vol. LXXVI, Núm. 230, Enero-Marzo 2010, 41-61
ISSN 2154-4794 (Electrónico) 
interior do livro. As palavras têm mais de um referencial. Diferentemente do processo unificador do qual nos falam os romances históricos da nação, Caminhos e fronteiras produz um desequilíbrio, ao estabelecer um ideal de nação que mantém as diferenças e até mesmo se nutre delas.

O resultado desse projeto, consciente ou não, é decisivo para a estrutura da obra e se coaduna numa escrita da fronteira social, palmilhada como território textual que o autor busca através de um caminho delicado. Delicado porque diverso do projeto dos romances históricos, em que também o enredo e a língua fazem parte de um sistema que abre à força um território, derrubando as fronteiras para fixar a modernidade do Estado-nação. Sérgio Buarque caminha quase "respeitosamente" pelas veredas, retomando caminhos nativos, colocando-se no lugar daquele que aprende. Tal condição exige, ainda, uma escrita que percorra os caminhos de um mapa-enredo interno da compreensão; não daquele de que se apossa, mas mapa de si e do outro, colocados num mesmo plano cultural. Na afirmação do autor,

O fato de as bandeiras saídas de São Paulo, ora em direção ao Guairá, ora rumo ao sertão do alto São Francisco, terem já nas primeiras investidas atinado com o caminho mais apropriado mostra até onde se valeriam seus cabos de colaboração indígena. ...Da existência efetiva dessas vias já com caráter mais ou menos permanente, antes de iniciar-se a colonização, nada autoriza a duvidar. E ainda hoje, o traçado de muitas estradas de ferro parece concordar, no essencial, com os velhos caminhos de índios e bandeirantes, sinal de que sua localização não seria caprichosa. (26)

Também não deixa de ser curioso que, longe de se aproximar do espaço como sujeito da consciência total no chamado bird view - que é também o olhar do alto, da onisciência - o livro se inicia pelo caminho. Essa perspectiva teria um bom contraponto na obra de Euclides da Cunha ou Fernand Braudel. Em ambos os casos, os autores se aproximam de seus objetos numa espécie de vôo geral, movimento do olho "que tudo vê", para depois, só muito lentamente, aproximar-se do espaço recortado.

O primeiro capítulo de Caminhos e fronteiras, intitulado "Veredas de pé posto", inverte a localização do autor, que se desdobra num ato epistêmico diverso. De fato, pode-se observar, nesses e noutros "pousos" do texto, certa sensibilidade historiográfica e cultural que, no entanto, parece produzir, a contrapelo, uma escrita carregada dessa geografia que persegue os atores nos seus gestos mínimos de encontro com o colonizador. Essa escrita, mais do que tudo, deve cobrir o perfil de todos os atores. A pretensão é produzir um passado, através desse espaço fluido do acontecer da fronteira, imprimindo uma nova feição possível de futuro. Contudo, o projeto, no plano da escrita, torna-se um desenho incomensurável, que já não é

$\begin{array}{llllll}\text { ISSN 0034-9631 (Impreso) } & \text { Revista Iberoamericana, Vol. LXXVI, Núm. 230, } & \text { Enero-Marzo 2154-4794 (Electrónico) }\end{array}$ 
representação. Parece confundir-se, querer reproduzir o “outro” naquilo que foi deixado de presença. Está aquém, mas, em alguns momentos, parece pretender estar além da escrita. Na fronteira, ponto da não-modernidade, o colonizador e os povos nativos merecem descrições igualadas em seus próprios termos; o processo de descrição das “técnicas adquiridas” pelos colonos é igualmente importante, e o resultado é, por fim, inevitavelmente relativizado. Sérgio Buarque mostra-se, assim, mais interessado no processo da fronteira do que no de sua ultrapassagem. Não é sem razão seu desabafo:

...o trabalho sobre as monções de povoado, com amplitude que já então se pretendia dar-lhe e que, afinal, veio a alcançar até certo ponto, representava apenas parte mínima de um todo orgânico, era praticamente inviável. Para chegar a bom termo, tal como fora concebido, esse plano requereria, talvez, mais do que uma vida humana. (10-11)

Este momento parece propício à introdução dos aspectos que explicam nossa própria cartografia de Caminhos e fronteiras, desenvolvida em torno da hipótese de que essa obra padece de um mal-estar difuso, que se desdobra numa escrita equivalente, cuja forma é bastante semelhante à sátira menipéia.

\section{A SÁTIRA MENIPÉIA COMO RECURSO HEURÍSTICO À LEITURA DE CAMINHOS E FRONTEIRAS}

Aafirmação de algum parentesco entre Caminhos e fronteiras e a sátira menipéia requer uma espécie de ante-sala. Primeiro estabelecemos, contradizendo a versão canônica, que Caminhos e fronteiras não é um "estudo de civilização material” avant la lettre, no sentido atribuído por Fernando Novais (1995) no prefácio da obra. Se Sérgio Buarque faz uso de uma história material, tal uso se deve menos a Braudel e mais às propostas descritivas dos viajantes dos séculos dezesseis a dezoito e dos antropólogos, em especial Marcel Mauss, no que diz respeito às técnicas corporais. ${ }^{4}$ Pode-se afirmar que a obra se inscreve numa discussão iniciada em duas frentes. Primeiro, a dos paulistas e sua importância no quadro da formação nacional: o bandeirantismo. Porém, ao conjunto de textos sobre os paulistas, ou

\footnotetext{
4 Os elogios que filiam Caminhos e fronteiras à história material de Braudel cometem o anacronismo típico da formação do cânone, tão bem comentado por Borges em "Kafka e seus precursores”. Os textos sobre fronteira e espaço e sobre a possibilidade de adaptação de uma cultura adventícia em Sérgio Buarque já aparecem nos anos 40. Monções é publicado em 1945. Mesmo as relações de amizade e proximidade intelectual entre os dois autores não autorizam tamanha inferência. Sérgio Buarque, em Caminhos e fronteiras, mantém semelhanças com Braudel em $O$ mediterrâneo e o mundo mediterrâneo na época de Felipe II, mas essa relação não é um diálogo que implique influência direta.
}

Revista Iberoamericana, Vol. LXXVI, Núm. 230, Enero-Marzo 2010, 41-61
ISSN 2154-4794 (Electrónico) 
sobre o interior paulista, Sérgio Buarque acresce uma teoria: a teoria da fronteira de Frederick Turner. Em Caminhos e fronteiras, embora prevaleça como questão última a identidade, tal problema não se apresenta novo. Nem mesmo a forma de desenvolvê-lo, no plano da escrita, é inovadora. O que se percebe é o rearranjo dos elementos pela introdução de um modelo explicativo. A segunda questão se relaciona com o corpus, em especial com a questão inaugurada em Raízes do Brasil, obra de Sérgio Buarque considerada central, que projetava um conjunto de argumentos sobre a impossibilidade de o Brasil superar seu legado ibérico, marcado pela tradição antimoderna. Contudo tal questão também se volta ao passado.

Se do ponto de vista argumentativo a questão centra-se no pensamento social brasileiro, nossa abordagem considera que esse pressuposto se reveste de uma determinada escrita em Caminhos e fronteiras. Nossa hipótese é a de que a escrita na obra sofre uma tensão do objetivo - o da construção nacional pela manutenção das culturas envolvidas. Do ponto de vista da escrita, a tensão criada pela escolha da construção da nação pela via adaptativa e pela continuidade de hábitos de uma cultura na outra gera uma forma delongada de texto. Sua expressão será mais bem compreendida, em nossa leitura, no marco da sátira menipéia. Trabalhada por Bakhtin e Northrop Frye (1973), e tomada como “anatomismo”, a sátira menipéia torna-se um importante recurso, na medida que é um discurso que descentraliza e possui caráter epistemológico inovador, podendo ser tomada como elemento hermenêutico. ${ }^{5}$

De fato, interessa-nos em especial uma subespécie do gênero menipeu: a anatomia, a partir do qual balizaremos nossa análise do texto de Sérgio Buarque. Além do sentido original da palavra "sátira", o de satura - cheio, completo -, o termo "anatomia", de raiz indo-européia, significa cortar, dissecar. A anatomia envolve, ainda, o manejo de uma enciclopédica erudição.

É a exuberância no trato do conhecimento que conecta Caminhos e fronteiras, Monções e Extremo Oeste à sátira menipéia. Com efeito, mais de um autor fez notar a imensa erudição que, embora presente desde os primeiros escritos, aparece nesses trabalhos, e talvez de maneira mais sistematizada em Caminhos e fronteiras. Muitos dos assuntos aí tratados são retomados em Monções e Extremo Oeste. Porém, se aliarmos tal erudição não apenas à cientificidade, mas também à prática de uma

\footnotetext{
5 Dissertar sobre os problemas epistemológicos que permeiam o método classificatório em muito extrapola o objetivo deste trabalho. A classificação do trabalho de Sérgio Buarque como sátira menipéia será adotada aqui com base no conceito de tipo ideal (Weber, 1989). Trata-se de uma construção metodológica, um recurso heurístico que, se não é inteiramente arbitrário e mantém com o "objeto" relações de correspondência e elucidação, encontra-se, por outro lado, impregnado de significações nascidas de uma leitura interessada desse "objeto".
}

$\begin{array}{llllll}\text { ISSN 0034-9631 (Impreso) } & \text { Revista Iberoamericana, Vol. LXXVI, Núm. 230, } & \text { Enero-Marzo 2154-4794 (Electrónico) }\end{array}$ 
"história total”, 6 poderemos inscrever-lhe um papel funcional: o da "anatomia"/ sátira menipéia. Talvez, e esta é nossa hipótese, o de uma anatomia da colonização brasileira. Qualquer totalidade, contudo, só pode ser buscada na ordem da linguagem, mesmo que desde seu início tal projeto esteja fadado ao fracasso. Assim, é na escrita que essa compreensão “total” da colonização será buscada. Como anatomia, deve dissecar, pormenorizar, menos como método do que como criação.

Como processo de escrever, baseado na anatomia, segue-se uma espécie de protocolo, que utiliza em primeiro plano a divisio-figura de linguagem que subdivide um tópico em inúmeras partes. Caminhos e fronteiras, em sua edição de 1995, contém um índice remissivo. Vejamos um exercício da divisio. As plantas, por exemplo, se dividem segundo a lógica da tese da fronteira que supõe a adaptação da população adventícia às condições nativas e às dificuldades na busca por sobrevivência. Assim temos: as plantas que se utilizam para obter água, no capítulo 2. Seus nomes são também um novo espaço construído na linguagem, na medida em que não se referem exatamente aos equivalentes dos colonizadores. Como ocupador, o historiador se ocupa no texto à maneira do adventício: deve apreender, adaptar-se. Na seqüência se aprende, pois, que “... os meios de que dispunham, tanto índios como sertanistas, quando procuravam algum veio d’água em lugar onde nada indicava sua presença, escapam, todavia, a uma análise precisa e objetiva” (37) e, por essa razão, é longa a lista: árvore-fonte, árvore-rio (samaritana dos sertões), escapu ou yçapy de Dobrizhoffer ${ }^{7}$, umari, a árvore rabo-de-bugio, também conhecida por árvore que chora ou Maria-preta, raiz de umbuzeiro, o mandacaru ou monducuru ou caraguatás. Observe-se que Sérgio Buarque redescreve as plantas, aproximando-as de outras designações possíveis, num reconhecimento de que as nomeações são arbitrárias e que o tempo é de adaptação, mas também como a nos alertar da arbitrariedade entre "as palavras e as coisas".

Na seqüência da divisio, o capítulo 4, "Iguarias de bugre”, trata de alimentos que o adventício apreendeu. Nesse momento, também são contempladas as plantas que o gentio oferecia como forma de se alimentar em condições de "sertões famintos". Segue-se, novamente, a lista: raízes de guariba ou guareá, grelos de samambaia, içá torrada, pinhão ou ibá, jabuticaba, guarirobas, grumixamas, pitangas, cambucis, ananases, articuns e o jataí.

\footnotetext{
"História total" pode ser considerado como um dos conceitos fundamentais dos Annales . É com Braudel e seu livro $O$ mediterrâneo e o mundo à época de Felipe II que os historiadores julgam que se realiza a prática desse conceito. Em resumo, significa que o contexto a considerar é bastante ampliado, levando em consideração desde os fatores econômicas até os fatores psicológicos, passando pela geografia, sociologia, antropologia e até mesmo mais tarde pela própria psicanálise. Para uma critica desse modelo historiográfico, ver em especial a critica de Levi-Strauss (1997).

7 Padre Martim Dobrizhoffer, jesuíta catequista, escreveu sobre a língua tupi-guarani.
}

Revista Iberoamericana, Vol. LXXVI, Núm. 230, Enero-Marzo 2010, 41-61
ISSN 2154-4794 (Electrónico) 
Seguindo a "tese da fronteira", Sérgio Buarque enumera as plantas medicinais no capítulo 6, "Boticas da natureza", e novamente segue afirmando "[que] foi certamente no contato assíduo do sertão e de seus habitantes que o paulista terá apurado as primeiras e vagas noções de uma arte de curar mais em consonância com o nosso ambiente e nossa natureza” (76). Esse item é indicado como de difícil estabelecimento entre o que era nativo e o que era próprio de colono, mesmo porque ambas culturas atribuíam poderes de cura a atitudes de crença e, nesse sentido, haveria um ambiente comum. É também por tais razões que “... práticas indígenas, que tinham todos os requisitos para alarmar ou escandalizar europeus, encontraram, por outro lado, acolhida inesperadamente favorável” (78). O alerta é para o solo comum das práticas imaginativas que são partilhadas. Não há estranhamento.

Sobre as rotas e caminhos, temos: os caminhos dos índios, no capítulo 1, e as rotas de comércio, no capítulo 9. Também seguem a mesma lógica da fronteiraaprendizado e adaptação. Para completar o exercício da divisio, para tudo há um nome, uma espécie. Como Braudel, Sérgio Buarque utiliza a dendrologia (estudo das árvores), a geografia, a topografia, a hidrografia. A exemplo de Braudel, Caminhos e fronteiras (especialmente o capítulo 2) e Monções listam as árvores - palmeira, guacunã, buriti -, os nomes das plantas - bromélia, fumo, erva de santana -, dos rios e águas - Rio Tiête, Rio Comprido, Rio Tibaji, Pardo, as águas das plantas, as águas das chuvas, etc. No capítulo "A cera e o mel”, os detalhes exigiram de Sérgio Buarque um trabalho de meses.

Não se trata de desacreditar toda erudição, mas apenas de sugerir sua capacidade de propor, nesse e em outros casos, uma representação histórica não apenas em seu conteúdo ou na intenção de informar minuciosamente. Trata-se, antes de tudo, de rever a fusão entre forma e conteúdo, tão rejeitada pela história após Ranke, que fez da escrita meio, no máximo estilo. Numa aproximação é possível dizer que a demora nos detalhes é tanta, que cada capítulo parece dispensar o outro. Como a dizer que para passar ao estágio seguinte é preciso adaptar-se ao nativo. A linguagem cumpre esse papel, tornando o que é próprio, alheio.

O processo de adaptação à fronteira é, portanto, assegurado numa escrita que parece não ter fim, transmitindo a sensação de morosidade. Se a obra de Turner expressa-se numa narrativa dramática, mas ao mesmo tempo épica, testemunhando a força da construção do homem norte-americano, a narrativa sergiana parece se envolver com os nativos, como que dedicada ao processo em si e menos preocupada com o elemento vencedor, se é que haverá algum. Em muitas passagens Sérgio Buarque lembra ao leitor que as práticas que descreve ainda se encontravam presentes à época em que escrevia seus ensaios. O processo da fronteira do qual se apropriou inicialmente, a teoria de Turner, parece se desvanecer nesses momentos, porque parece não haver ultrapassagem.

Revista Iberoamericana, Vol. LXXVI, Núm. 230, Enero-Marzo 2010, 41-61
ISSN 2154-4794 (Electrónico) 
VOZES NA FRONTEIRA

Os toscos desenhos e os nomes estropiados desorientam, não raro, quem pretenda servir-se desses documentos para a elucidação de algumponto obscuro de nossa geografia histórica. (Caminhos e fronteiras 19)

O trecho citado apresenta, sobretudo, o desarranjo produzido por um universo cultural híbrido, no qual os nomes sempre podem ser vários. Já nos primeiros parágrafos, ao tratar do sistema de pistas deixadas pelos caminhantes para encontrar a volta, Sérgio Buarque informa: "Era o processo chamado ibapaá, segundo Montoya, caapeno, segundo padre João Daniel, cuapaba, segundo Martius, ou ainda caapepena, segundo Stradelli” (11). Se os desenhos não são confiáveis, tampouco são os nomes. Significantes e significados são suspensos, lembrando a arbitrariedade de ambos os lados. A descrição que busca tornar o estranho próximo, nomeando o objeto, acaba por desfamiliarizá-lo ainda mais.

Talvez o intento seja voltar ao múltiplo para reinaugurar sua unicidade. Mas, uma vez afastada a ipseidade das palavras, é necessário, ironicamente, recorrer com mais intensidade às próprias palavras. Lembremos que, à história, não foi dado engendrar uma linguagem técnica, absolutamente irredutível aos termos do senso comum, linguagem que, pelo simples fato de constituir-se, teria o condão de assinalar a elevação da História à estatura de disciplina científica.

Sérgio Buarque não substitui a fala errante, que parece não incomodá-lo. Sua estratégia é de outra natureza. Ao incômodo do múltiplo, responde por uma acentuação e uma rearrumação original. Voltemos aos relatos dos viajantes, um dos principais recursos desde os primeiros parágrafos de Caminhos e fronteiras. Segundo Süssekind (1990), as narrativas de viagem e romances baseados nesses relatos se desdobraram, sobretudo, no desenho de um Brasil-natureza, marcado pela força dos trópicos e por potencialidades econômicas prontas a serem exploradas. Tal construção se prende à idéia de origem e fundação. Contudo, “mais para a miragem do que para a paisagem, nutre-se abundantemente das descrições dos viajantes que passam por aqui. Dos cronistas acaba-se por tomar algo para além dos desenhos de vistas e das visões às vezes paradisíacas” (Süssekind 33).

Esses relatos, mais do que retratar, desenham uma paisagem atemporal, uma “essência meta-histórica” (37), apresentada como terra nulis e paisagem útil. Nesse projeto, a descrição e a cartografia se tornaram os primeiros meios de transformar o distante em próximo. Tais relatos tiveram tamanha força fundadora, que se estabeleceram como fonte documental. Tanto a prosa histórica sobre os primórdios do Brasil, quanto os romances ficcionais do século dezenove retomaram aquelas descrições, mesmo que em escala e forma diferentes.

Revista Iberoamericana, Vol. LXXVI, Núm. 230, Enero-Marzo 2010, 41-61
ISSN 2154-4794 (Electrónico) 
Sérgio Buarque presta, a seu modo, a mesma reverência. Suas fontes são, em grande parte, a dos cronistas de época, cartas, anotações de viagem. Porém, ao convocar o testemunho dessas fontes documentais, Sérgio Buarque o faz de maneira diferente. Usa exaustivamente uma massa de citações, que não apresentam, entretanto, uma hierarquia de credibilidade. O modus operandi exaure o evento, ao rodeá-lo de informações que não geram necessariamente sua cabal definição. As várias fontes e referências são articuladas por uma voz, nunca categórica, que dá preferência a expressões não conclusivas. Porém, se a presença de uma indeterminação deliberada na própria escrita é indiscutível, cria um embaraço quanto à função de tais citações na narrativa. Acompanhadas de dúvidas, perde-se aquele papel canônico que a apresentação das fontes sempre ocupou na escrita histórica: a cada afirmação do historiador-narrador deve seguir-se uma outra voz que, apresentando-se como a própria coisa em si, anula a voz do historiador, ao mesmo tempo em que lhe concede, indiretamente, a autoridade do saber. É nessa alternância entre a voz do narrador e a da fonte que se insinua o próprio da comunicação histórica.

No texto sergiano, várias fontes trazidas ao mesmo plano instauram uma verdadeira polifonia no interior da escrita histórica, classicamente considerada como monológica. Enquanto método, trata-se de um tipo de symposium, uma das características da sátira menipéia, em que um diálogo ou colóquio centra-se com maior interesse na exposição do conflito de idéias do que na definição de um personagem ou mesmo de um fato. Segundo Frye, o symposium deve ser compreendido como forma de gerar conhecimento através da competição retórica, na qual os vários argumentos e informações podem criar desconforto e dúvida. Esse novo modelo de retórica não apenas comunica conhecimento, mas é ele próprio um método de investigação. De maneira genérica, a estratégia pode ser duplamente considerada anatômica, pois, se disseca o objeto por um excesso informativo, o faz sob a égide da digressio, refletindo um modo de conhecer que se "alonga".

Em Caminhos e fronteiras, as muitas referências, colocadas em igual patamar, instauram uma verdadeira polifonia. Contudo, mais do que polifonia, o trabalho seria mais bem considerado, nos termos bakhtinianos, se adotássemos a heteroglossia. A diferença se coloca na qualificação das vozes. Bakhtin trabalhou com obras ficcionais, e o romance polifônico é um gênero que surge a partir do século dezenove. Nele, segundo Bakhtin, se abre uma arena textual em que várias vozes estão dispostas numa complexidade discursiva. Tais romances são polifônicos na medida em que resistem à totalização, e seus personagens surgem com liberdade, produzindo um conflito de idéias no interior do texto.

No caso do texto do historiador, como também no texto do antropólogo e do etnógrafo, as situações, embora com várias semelhanças, possuem pelo menos um distanciamento. Apesar de podermos considerar as fontes (os viajantes, em

Revista Iberoamericana, Vol. LXXVI, Núm. 230, Enero-Marzo 2010, 41-61
ISSN 2154-4794 (Electrónico) 
Caminhos e fronteiras) ou o trabalho de campo (etnografia) como vozes internas ao texto, elas ainda são dominadas pelo caráter autoral. Mais do que isso, enquanto nos romances os personagens são inventados, no texto histórico ou etnográfico as fontes são (ou foram) indivíduos de existência conferida. Tal afirmação não destrói a idéia das vozes no texto, apenas lhes confere outro status: os informantes/fontes são sobre-determinados por uma rede contextual de origem.

Assim, a estratégia do texto sergiano se abre por um lado, mas se reordena por outro. As vozes vão se sucedendo no texto aparentemente com autoridade própria, o que é um atributo do discurso da história (Barthes, "O discurso da história”): fazer entrar a autoridade do documento, criando assim o "efeito de real", ou, de outra forma, reforçando a voz do historiador. Porém, também é verdade que a forma descozida do texto sergiano deixa margem para que se passe de uma fala à outra sem que o autor faça, em todas as vezes, a clara pontuação da marcação da autoridade. Nesse sentido, apenas se ensaia no texto uma estratégia de "dar voz" para estabelecer em seu lugar um symposium.

Tendo esse painel em mente, o enredo e o método de Sérgio Buarque sugerem uma outra construção. Nosso autor evoca o cânone dos relatos fundadores e utiliza-os numa clave diversa daquela apontada por Süssekind, a do Brasil-paisagem, natureza sem cultura. Por outro lado, o recurso àqueles relatos tem algo de tortuoso: surgem no texto a dar o seu testemunho por questões as mais diversas e sem nenhuma ordem cronológica. Com efeito, o retorno e a performance dessas vozes podem não apenas trazer ao agora o passado em forma de pensamento e informação, mas sobretudo reescrever, redesenhar, contar de novo a história. O método remete à impossibilidade de voltar àquele momento sem a referência às fontes, sem o gesto arquivístico do historiador cuidadoso do seu métier. Porém, exatamente ao trazê-las à cena e expô-las saturadamente, o autor cria outra possibilidade de leitura, uma vez que as informações não se excluem. Vejamos uma passagem sobre as armas:

Jean de Léry, que assistiu a essas tentativas, diz-nos que para fazer funcionar o arcabuz, os índios necessitavam de três pessoas .... O interesse que as armas de fogo provocavam entre esses índios vinha em parte da detonação, mas sobretudo de não poderem perceber o projétil em sua trajetória. Mas esse interesse logo se dissipou ao verificarem que o tempo consumido em carregar e disparar um arcabuz dava para cinco ou seis tiros de frecha: "tant y a neanmoins qu'ayant cogneu l'artifice, disans (comme est-il vray), qu'avec leurs arcs ils aurount plus tost delasché cinc ou six flesches qu'on aura chargé \& tire um coup d'arquebuze, ils commençoyent de s'esseure à l'encontre" [nota Léry]. De arco e frecha andam armados os filhos de João Ramalho "muitos em número e todos de má casta”, disse Vasconcelos. É conhecida a resposta de um deles, quando lhe acenaram com os rigores do Santo Ofício: “Acabarei com a Inquisição a frechas”. Muito mais tarde, já em 1614, o desembargador Manuel Jácome Bravo, da Relação do Estado

Revista Iberoamericana, Vol. LXXVI, Núm. 230, Enero-Marzo 2010, 41-61
ISSN 2154-4794 (Electrónico) 
do Brasil, achando-se em São Paulo em correição, é advertido pelos moradores, por meio de frechas que lhe passam rente à cabeça, de que deve renunciar ao prosseguimento de suas devassas e abandonar o mais depressa possível as terras piratininganas [nota Taunay]. Mesmo em documentos públicos, como as cartas de sesmarias, lêem-se coisas deste teor: “... um capão de mato virgem, que terá quatro ou cinco tiros de frechas de comprido e dois tiros de largo, pouco mais ou menos ... [nota Documentos do Arquivo de São Paulo]. (Holanda, Caminhos e fronteiras 66-67; ênfases da autora)

Aprimeira entrada de Léry no texto éindicada diretamente. Aseguinteéindireta e se dá através de nota ao final do livro. A segunda fonte, Vasconcelos, não contém maiores informações e deduz-se que o dado sobre os filhos de João Ramalho seja o mesmo: nesse caso a indicação também é dada por referência à nota que indica, por sua vez, um trabalho de Taunay, “cf. História Seicentista da Vila de São Paulo”. A última fonte citada num espaço de três parágrafos também leva o leitor às notas finais. Neste caso, o trabalho não tem autoria, o que indica documentação esparsa: “Sesmarias, documentos do Arquivo do Estado de São Paulo, 1, São Paulo, 1921”. A proliferação de informação/informantes se arrasta ao longo do trabalho.

Trata-se de uma escrita em palimpsesto que, mantendo algo da anterior, reutiliza o mesmo papel para aí gravar uma outra história. Observa-se em Sérgio Buarque a preocupação com vocábulos da época, o que às vezes confunde o leitor: afinal, quem fala aqui? $\mathrm{O}$ narrador-historiador ou a fonte, aquele testemunho antigo? Provavelmente ambos. Essa escrita "difícil” resiste ao movimento solto e fluido, talvez porque a tarefa seja ela própria "movediça”.

Oresultado, porém, alcança outro horizonte. Se os relatos de viagens construíram a imagem fundadora do Brasil como natureza grandiosa mas a-histórica, Sérgio Buarque, cuidando dos mesmos materiais, trata de dotá-la de novas cores - as do movimento e da história. Assim, é como um quebra-cabeças e com uma espécie de instinto coletor ${ }^{8}$ que Caminhos e fronteiras se constrói. Não é pela omissão, nem pelo inédito, mas pelo sempre dito, desde sempre lá, que a história se faz. Sérgio aproveita-se da mobilidade do viajante, dos relatos de quem "viu", de quem esteve lá, como quem acredita no realismo ingênuo dos sentidos. Cita-os com pouquíssimas ressalvas, ${ }^{9}$ como a transferir seu estatuto de verdade para seu próprio trabalho, fazendo-os porém submergirem à ordem de seu relato.

\footnotetext{
8 Segundo Frye, uma das características da sátira menipéia é a construção do texto por coleta como se o autor construísse seu discurso por espécie de bricolage o que pode também remeter ao ensaio de Walter Benjamin "Sobre o conceito de história”.

9 Sérgio Buarque parece muitas vezes "generoso" para com os relatos dos séculos dezessete e dezoito. Sobre o padre Fernão Jardim, por exemplo, comenta: "Terá havido muito exagero nas informações em que se fiou o cronista inaciano, mas o exagero é companheiro da surpresa” (Holanda, Caminhos e fronteiras 37).
}

$\begin{array}{llllll}\text { ISSN 0034-9631 (Impreso) } & \text { Revista Iberoamericana, Vol. LXXVI, Núm. 230, } & \text { Enero-Marzo 2154-4794 (Electrónico) }\end{array}$ 
Talvez fosse excessivo afirmar que é de uma outra fundação brasileira que trata Sérgio Buarque. Porém, com certeza, uma nova paisagem emerge de Caminhos e fronteiras e Monções. Àquela natureza em forma de "rede atemporalizada" (Sussekind 1990) sobrepõe-se agora uma outra, marcada pelo gesto humano, pelo gesto dos nativos e dos portugueses na tomada da terra.O “itinerário do texto" (Dias 13) vai além, apenas, "dos temas em movimento no tempo e da urdidura intricada dos fatos miúdos no seu processo de significação" (13). Esse intricado recurso metodológico do cortar, colar e encadear, como manuseio literário, prova que não se trata de fazer ou não literatura, mas daquilo que o historiador utiliza.

O tema, saturadamente exposto, é apreendido menos nas minúcias do que nas direções cambiantes que toma a escrita. A palavra "caminho" não pertence aqui apenas ao mundo puramente objetivo, mas ao próprio texto, direta ou indiretamente. Direta, ao tratar literalmente dos caminhos percorridos pelos bandeirantes e nativos nos tempos da colonização em Caminhos e fronteiras. Direta, também, nos caminhos pluviais em Monções. Mas indiretamente, na construção textual, que como tal não se limita à forma, mas reinstaura e impressiona o objeto, de tal modo que é impossível prescindir de um para encontrar o outro. O processo pode ser compreendido como uma técnica de dificultar as formas e alongar a percepção de qualquer objeto, uma vez que o processo de percepção é ele mesmo estético e não puramente lógico. Assim, o ziguezague do texto, ou sua aparente não direção, tem o mesmo efeito da vereda, do caminho: é no passo a passo que se cumpre sua efetividade.

CONCLUSÃO: TEXTO HISTÓRICO E IRONIA

\footnotetext{
Não está em mapa algum; os lugares de verdade nunca estão.
}

Herman Melville, Moby-Dick

Acitação de Melville poderia serperfeita para concluirnossa análise de Caminhos e fronteiras de Sérgio Buarque. Contudo, falta refletir sobre dois pontos que nos parecem significativos, se não para fechar este trabalho, pelo menos para instigar a continuidade das pesquisas limítrofes entre os campos da literatura e história.

Em primeiro lugar, o fato de que tomamos aqui como premissa epistemológica que a história e a antropologia são devedoras de processos que passam pela linguagem não apenas em seu processo estético (estilo do historiador), mas mais do que isto, a linguagem constrói tanto quanto as fontes o objeto do historiador. Embora essa não seja a discussão mais significativa para este análise, a afirmação se atrela à seguinte: a de que a narrativa de Caminhos e fronteiras produz ao final e ao cabo um perspectiva irônica da história da ocupação.

Revista Iberoamericana, Vol. LXXVI, Núm. 230, Enero-Marzo 2010, 41-61
ISSN 2154-4794 (Electrónico) 
A idéia de ironia é tomada, aqui, no sentido de Hayden White (1991), mas também no de Richard Rorty (1994). Para o primeiro, a ironia se processa sempre que se “... afirma tacitamente a negação do que no nível literal é afirmado positivamente, ou o inverso” (51). Segundo o autor de Metahistória, tal atitude revela um sujeito capaz de reconhecer o mundo da linguagem de um ponto de vista “problemático”. Em outras palavras, significa um sujeito, autor, falante ou leitor, que se coloca no mundo a partir da dúvida; sua posição é cética e, portanto, seu protocolo lingüístico é inconstante. Para Rorty, o ironista é aquele que sabe o que é, definido por um vocabulário, mas poderia ser definido (provavelmente o será) por um outro vocabulário. Além disso, não existem vocabulários mais autênticos que outros. ${ }^{10}$

Tanto na versão de White, mais afeita às questões da história da consciência histórica, como na de Rorty, que propõe um desenho político, uma utopia, o resultado do conceito de ironia é o mesmo: a idéia de um descolamento entre as palavras e as coisas. Quanto ao nosso objeto e à dissecação a que é submetido - ao se promover sobre ele inúmeras narrativas e descrições -, trata-se de uma produção de caráter irônico na medida em que as redescrições não se sobrepõem umas às outras num processo hierárquico, senão em uma nova descrição: um outro contar, uma descrição de um outro detalhe; o rodear de quem diz e desdiz.

De qualquer modo, é possível reafirmar a afinidade historicista de Sérgio Buarque a esse universo ironista. O historismo ao qual se referia nosso autor se filiava à corrente alemã de Wilhelm Dilthey (1996) e se opunha ao conceito de historicismo que se baseava numa proposta de leis gerais ou um devir histórico único. No entanto, o historismo ensinava como era possível, dentro de uma concepção relativista (irônica), trazer ordem ao caos. Tal performance foi atingida nos escritos de Humboldt e de Ranke, ${ }^{11}$ por exemplo, através da idéia histórica, por meio da qual o historiador deveria ver o passado. ${ }^{12}$

${ }^{10}$ Nosso intento não é uma análise filosófica de Rorty; nesse sentido sua apresentação é bastante sucinta, contudo sua posição provém de uma tradição considerada ou nomeada anti-metafísica. Suas idéias, além de rejeitarem a concepção de que existe uma verdade ou sentido único, renunciam ao caráter representacional da linguagem em relação ao mundo. Para Rorty, não existe um ponto de vista que esteja fora da linguagem e, portanto, todo conhecimento é contingente e sempre o será.

${ }^{11}$ Para um entendimento diverso do usual que categoriza Ranke como um "positivista", ver especialmente Ankersmit 2001.

12 A discussão entre historicismo e historismo remonta à questão sobre se há um sentido da História. Este é um dos conceitos-chave da historiografia e apresenta uma longa fortuna crítica que ainda continua em debate. De maneira geral os historicistas entendem a história como dotada de uma necessidade ou um "sentido" e provavelmente seu maior expoente seja Hegel. Os historistas se situam num outro lado, e são considerados muitas vezes como relativistas porque entendem que a história deve ser compreendida a partir dos sujeitos. Embora pareça simples a discussão sobre o devido conceito, a filiação de muitos historiadores é bastante delicada. Sobre este assunto ver especialmente Ankersmit (2001) e Koselleck (2002).

ISSN 0034-9631 (Impreso) 
As afinidades entre a ironia e o historismo se expressam na escrita sergiana através do texto, numa estruturação que aqui aproximamos à sátira menipéia. Tal gênero da sátira menipéia nos permitiu ler a fronteira sergiana como lugar onde ocorreria, a exemplo da fronteira norte-americana (como na tese de Turner), o lugar privilegiado da produção de uma cultura nacional. O anatomismo, característica inerente da sátira, investe o texto de uma saturação que encontra na ironia e no historismo o seu correlato.

Contudo, os projetos nacionais estão bemmais próximos aum desenho romântico do que irônico. Apesar de todas as discussões e acontecimentos contemporâneos, os projetos nacionais ocuparam, e ainda ocupam, uma centralidade cultural indiscutível. Se tal afirmação é pertinente, como se coloca a versão de um pensar historista, portanto irônico, dentro de uma meta romântica? Parece-nos que esse é um dos nós górdios mais intrigantes da escrita sergiana. De fato, a escrita de Sérgio Buarque, bem como a de outros autores não-ficcionais, carece, ainda, de análises mais detalhadas. Com exceção das obras de Euclides da Cunha - que também não se inscreve por completo no campo da não-ficcionalidade.

Concordamos, assim, com Rorty e suas redescrições. Porém, o tropo irônico nem sempre é único, e as metáforas, como bem assinala F. R. Ankersmit (1994), podem viabilizar uma postura intermediária que, vinculada a um projeto englobador qualquer, é capaz de promover um desequilíbrio intenso no texto. Parece ser este o caso de Sérgio Buarque: a imaginação da fronteira se desenrola na direção de uma forma irônica, que não produz uma única metáfora habilitada a substituir a "coisa", no caso, "a nação". As metáforas promovem outros dizeres, substituições sem fim, elas próprias irônicas. Em outras palavras, o projeto se choca com o que efetivamente Sérgio Buarque produz. O texto, lido àluz de um projeto de homogeneizaçãonacional, não reproduz, no nível da escrita, tal projeto. Ao contrário, parece desmenti-lo. Seu alongamento, tratado aqui através da sátira menipéia, mostrou uma outra leitura, no caso, como o anatomismo, que se empenha numa dissecação sem fim. Como mostramos, a narrativa sergiana traz ao texto todas culturas, rodeando a todas com igual cuidado. Nesse sentido, a fronteira parece continuar a existir como qualidade, como lugar de todas e sem ultrapassagem. Se para um hibridismo a proposta parece interessante, ela pouco responde quando lembramos que Sérgio Buarque narra em seu livro a ocupação das terras do interior do Brasil pelos portugueses no século dezoito. Não lhe interessa o todo, senão os pedaços, as partes, ou como bem nos lembra Finazzi-Agrò:

Nesta ótica, Caminhos e fronteiras poderia ser visto também como uma espécie de coleção - num sentido ainda benjaminiano - de eventos pretéritos, ou melhor, como um conjunto de "restos”, de "cacos" de uma história integral e inatingível na sua plenitude, da qual eles guardam todavia uma parcela, um reflexo embaçado:

Revista Iberoamericana, Vol. LXXVI, Núm. 230, Enero-Marzo 2010, 41-61
ISSN 2154-4794 (Electrónico) 
apenas no seu combinar-se, dentro do espaço precário e nostálgico do livro, essas ruínas de um passado perfeito conseguem reencontrar sua razão de ser, a sua necessidade e a sua evidência, embora longe de qualquer ilusão de continuidade ou de coerência, fora de qualquer organicismo conseqüencial e causalista. ("A trama e o texto” 156)

É nesse sentido que a estrutura de Caminhos e fronteiras parece se mover em direção nenhuma. Também os homens não se movem em direção progressiva e, mesmo as transformações, típicas de uma cultura de fronteira, não levam necessariamente a uma situação melhor. O que fica, ao fim, é uma paisagem absurdamente impressionista, que, vista à curta distância, torna-se mero emaranhado de traços. O traço, a linha, a cor e seu manuseio precisam ser de grande riqueza estética. Uma história que se faz pela impressão que causa, e não pela explicação lógica que almeja ou sugere operar.

\section{OBRAS CITADAS}

Anderson, Benedict. Nação e consciência nacional. São Paulo: Ática, 1989.

Ankersmit, F. R. History and Tropology: the Rise and Fall of Metaphor. Berkeley, Los Angeles, London: U of California P, 1994.

Ankersmit, F. R. Historical Representation. Stanford: Stanford UP, 2001.

Bakhtin, Mikhail. A cultura popular na Idade Média e no Renascimento: o contexto de François Rabelais. Rio de Janeiro: Annablume, 2002.

"Formas de tempo e de cronotopo no romance". Questões de literatura e de estética: a teoria do romance. São Paulo: Unesp-Ucitec, 1998. 211-348.

Problemas da poética de Dostoievski. Rio de Janeiro: Forense, 2002.

Barthes, Roland. "O discurso da história”. O rumor da língua. Lisboa: Edições 70, 1987. 121-30.

Benjamin, Walter. "Sobre o conceito de história". Obras escolhidas I: Magia e técnica, arte e política. São Paulo: Brasiliense, 1985. 222-35.

Borges, Jorge Luis. Otras inquisiciones. Madrid: Alianza, 1999.

Braudel, Fernand. Mediterrâneo e o mundo mediterrâneo na época de Felipe II. [s.n.t.].

Cunha, Euclides da. Os Sertões. São Paulo: Ática, 2003.

Dias, Maria Odila Leite da Silva. “Sérgio Buarque de Holanda, historiador”. Sérgio Buarque de Holanda, historiador. Maria Odila Leite da Silva Dias, org. São Paulo: Ática, 1985. 7-64.

Dilthey, Wilhelm. Introducción a las ciencias del espíritu: ensayo de una fundamentación del estudio de la sociedad. 2. ed. [S.l.]: [s.n.], 1996.

ISSN 0034-9631 (Impreso) 
Finazzi-Agrò, Ettore. Um lugar do tamanho do mundo: tempos e espaços da ficção em João Guimarães Rosa. Belo Horizonte: Ed. UFMG, 2001.

"A trama e o texto: história com figuras". Um historiador nas fronteiras: o Brasil de Sérgio Buarque de Holanda. Sandra Jatahy Pesavento, org. Belo Horizonte: Ed. UFMG, 2005. 143-59.

Gellner, Ernest. Nations and Nationalism. Lisboa: Gradiva, 1993.

Frye, Northrop. Anatomia da crítica. São Paulo: Cultrix, 1973.

Holanda, Sérgio Buarque de. Caminhos e fronteiras. São Paulo: Companhia das Letras, 1995.

Extremo Oeste. São Paulo: Brasiliense/Secretaria de Estado da Cultura, 1986.

Monções. São Paulo: Brasiliense, 2000.

Raízes do Brasil. 12ํe․ Rio de Janeiro: José Olympio, 1983.

Humboldt, Wilhelm von. "Sobre a tarefa do historiador". Pedro Spindola Pereira Caldas e Johannes Kretschmer, trads. Anima: Revista de História [Rio de Janeiro] (2001):79-89.

Koselleck, Reinhart. The Practice of Conceptual History: Timing History, Spacing Concepts. Stanford: Stanford UP, 2002.

Levi-Strauss, Claude. O pensamento selvagem. Campinas: Papirus, 1997.

Mauss, Marcel. Antropologia. Roberto Cardoso de Oliveira, org. São Paulo: Ática, 1979.

Moretti, Franco. Atlas do romance moderno europeu: 1800-1900. São Paulo: Boitempo, 2003.

Novais, Fernando. Prefácio. Caminhos fronteiras. De Sérgio Buarque de Holanda. São Paulo: Companhia das Letras, 1995. 5-8.

Pushkin, Aleksandr Sergeevich. The Captain's Daughter. 1836. London: Hesperus, 2007.

Rorty, Richard. Contingência, ironia e solidariedade. Lisboa: Presença, 1994.

Scott, Walter, Sir. Waverley. 1814. Edinburgh : Edinburgh UP, 2007.

Sommer, Doris. Ficções de fundação: os romances nacionais da América Latina. Belo Horizonte: UFMG, 2004.

Süssekind, Flora. O Brasil não é longe daqui: o narrador, a viagem. São Paulo: Companhia das Letras, 1990.

Comentário a "Nota breve sobre Sérgio Buarque de Holanda” de Antonio Arnoni Prado. Rio de Janeiro. Sérgio Buarque de Holanda: $3^{\circ}$ Colóquio UERJ. Rio de Janeiro: Imago, 1992. 136-45.

Turner, Frederick Jackson. The Frontier in the American History. 1920. New York: Dover, 1996.

Weber, Max. Metodologia das ciências sociais. São Paulo: Cortez, 1989.

Revista Iberoamericana, Vol. LXXVI, Núm. 230, Enero-Marzo 2010, 41-61
ISSN 2154-4794 (Electrónico) 
Wegner, Robert. A conquista do Oeste: a fronteira na obra de Sérgio Buarque de Holanda. Belo Horizonte: UFMG, 2000.

White, Hayden. Metahistória. São Paulo: EDUSP, 1991.

ISSN 0034-9631 (Impreso) 
